\title{
El romance morisco Ensíllenme el potro rucio, atribuido a Liñán, y su parodia
}

\author{
The moorish ballad Ensillenme el potro rucio, \\ attributed to Liñán, and its parody
}

José Luis Pérez López

\begin{abstract}
RESUMEN: El romance «Ensíllenme el potro rucio» está atribuido a Pedro Liñán de Riaza en el manuscrito 973 de la Real Biblioteca de Palacio de Madrid. Se nos transmite en fuentes impresas y manuscritas. La versión de los impresos transmite un texto incompleto al que le faltan doce versos o tres coplas, lo cual se pone de relieve al compararlo con la parodia gongorina «Ensíllenme el asno rucio». El presente estudio pretende plantear y resolver estas dos cuestiones: editar el texto basándonos en todas las fuentes posibles, y atribuírselo al que, de acuerdo con la fuente manuscrita más antigua, fue su autor, Pedro Liñán de Riaza.
\end{abstract}

Palabras clave: Liñán de Riaza, Lope de Vega, romance idealista morisco, romance realista burlesco.

ABSTRACT: The Spanish ballad «Ensillenme el potro rucio» is attributed to Pedro Liñán de Riaza in manuscript 973 of the Royal Palace Library of Madrid. This romance has been transmitted by written and printed sources. The printed versions transmit an incomplete text that is missing 12 verses and 3 popular songs (coplas) which stands out when compared with the Gongoristic parody «Ensíllenme el asno rucio». This study aims to raise and resolve the following issues: editing the text based on all of the possible sources, and attributing it to its rightful author, according to the oldest handwritten source available, Pedro Liñán de Riaza.

Keywords: Liñán de Riaza, Lope de Vega, handwritten Spanish ballads, printed ballads, idealistic Moorish romance, realistic burlesque romance. 
El presente estudio forma parte de un proyecto de investigación más amplio que consiste en editar las obras de Pedro Liñán de Riaza, en el que nos hallamos ocupados en la actualidad. Para ello es necesario someter a juicio crítico las composiciones que son atribuidas a este poeta por alguna fuente antigua, como es el caso del romance que nos ocupa, atribuido a «Liñán» en el manuscrito 973 de la Real Biblioteca de Palacio de Madrid, manuscrito de procedencia salmantina.

La determinación de la autoría de un texto es la primera labor de carácter filológico que hay que acometer en los estudios literarios. Si no se hace así, se corre el riesgo de trabajar en el vacío, atribuyendo a un autor lo que pertenecería a otro. Por otra parte, para editar y estudiar la poesía del Siglo de Oro es necesario utilizar los cancioneros y romanceros manuscritos, sobre todo si se trata de romances anónimos del Romancero nuevo. Los críticos e historiadores de nuestra literatura que se han ocupado de «Ensíllenme el potro rucio» teniendo en cuenta solo las versiones textuales de las fuentes impresas (Las distintas Flores y el Romancero general) desconociendo y omitiendo la tradición manuscrita, han estado trabajando sobre un texto incompleto al que le faltan doce versos o tres coplas, por lo que sus conclusiones a la fuerza tienen que ser puestas en cuarentena. Si, además, estos autores no se han cuestionado la autoría de la obra y se la han atribuido sin más a Lope de Vega, se han podido estar escribiendo muchas páginas que, como consecuencia de estos desconocimientos y omisiones, ahora resultarían estupendos ejercicios de inventiva. El presente estudio pretende plantear y resolver estas dos cuestiones: editar el texto basándonos en todas las fuentes posibles, y atribuírselo, con garantías de autenticidad, a su autor.

El romance idealista morisco «Ensíllenme el potro rucio» se nos ha transmitido en cinco manuscritos y en cuatro impresos:

Manuscritos:

A. Ms. 973 de la Real Biblioteca de Palacio de Madrid, fechado en 15811586, ff. 403v-404r (Atribuido a «Liñán»). De procedencia salmantina. Véase José J. Labrador Herraiz, «Poesías inéditas del alcarreño Pedro Liñán de Riaza (1555?-1607)», en Selected Proceedings of the Pennylvania Foreign Language Conference, 1988, págs. 103-110; y José J. Labrador Herraiz, Ralph A. DiFranco y Lori Ann Bernard, «El manuscrito Fuentelsol (MP II-973) con poemas de Fray Luis de León, Fray Melchor de la Serna, Hurtado de Mendoza, Liñán, Góngora, Lope y otros», Analecta Malacitana, XX, 1, 1997, págs. 189-265.

B. Ms. 996 de Real Biblioteca de Palacio de Madrid, ff. 1r-2v. Fechado en 1595-1598. Hay edición moderna: Romancero de Palacio (Siglo XVI), 
ed. José J. Labrador Herraiz, Ralph A. DiFranco, Lori A. Bernard, prólogo de Juan Fernández Jiménez, Cleveland, Cancioneros Castellanos, 1999, número 1, págs. 3-4, de donde tomamos las variantes.

C. Ms. 3915 de la Biblioteca Nacional de España de Madrid (Cancionero de Jacinto López), f. 194v. Fechado en 1620.

D. Ms. 17556 de la Biblioteca Nacional de España de Madrid, ff. 4r-5r. Fechado hacia 1595. Hay edición moderna: Poesías barias y recreación de buenos ingenios, edición y estudio por Rita Golberg, 2 volúmenes, Madrid, Ediciones José Porrúa Turanzas, 1984, págs. 105-107, de donde tomamos las variantes.

E. Ms. B 2334 de la Hispanic Society of America de Nueva York, f. 80v81v. Descrito e inventariado por Antonio Rodríguez-Moñino, «Romancerillo de Sancho Rayón», en Curiosidades bibliográficas. Rebusca de libros viejos y papeles traspapelados, Madrid: Langa y Compañía, 1946, págs. 81-104.

Impresos ${ }^{1}$ :

F. Flor de varios romances nuevos y canciones... recopilados por... Pedro de Moncayo. Huesca, 1589, f. 7v. Editado por A. Rodríguez-Moñino, Las fuentes del Romancero general (Madrid 1600), Madrid, Real Academia Española, 1957, vol. I.

G. Flor de varios romances nuevos. Primera y segunda parte, recopilados por Pedro de Moncayo (Barcelona, 1591). Editado por A. RodríguezMoñino, Las fuentes del Romancero general (Madrid 1600), vol. II.

H. Flor de varios y nuevos romances. Primera, segunda y tercera parte. Textos de Pedro de Moncayo y Pedro de Flores (Lisboa, 1592), edición, notas e índices por Mario Demonte, vol. XIII de Las fuentes del Romancero general (Madrid 1600), Real Academia Española, Madrid, 1971.

\footnotetext{
${ }^{1}$ Se recoge también en los dos impresos siguientes: Flor de varios romances nuevos. Primera y segunda y tercera parte. Ahora nuevamente recopilados y puestos por orden, y añadidos muchos romances que se han cantado después de la primera impresión. Y corregidos por el bachiller Pedro de Moncayo, natural de Borja, Madrid, Pedro Gómez de Aragón, a costa de Francisco Enríquez, 1593, f. 3v; y Flor de varios y nuevos romances, primera y segunda parte. Ahora nuevamente recopilados y puestos por orden, por Andrés de Villalta natural de Valencia. Añadiose ahora nuevamente la tercera parte por Felipe Mey, mercader de libros: Tercera parte de Flor de varios romances, recopilados por Felipe Mey, Valencia, Miguel Prados, 1593, f. 6. Véase para ambos libros la edición de Antonio Rodríguez-Moñino, Las fuentes del Romancero general (Madrid, 1600), vol. III, Flor de varios romances nuevos. Tercera parte. Textos de P. Moncayo y Felipe Mey (Madrid 1593, Valencia, 1593), Madrid, RAE, 1957; en esta obra solo se editan las Terceras partes, por lo que no aparece «Ensíllenme el potro rucio». En nuestra edición del texto no hemos podido tener en cuenta estas dos fuentes, suplidas perfectamente por F, G y H.
} 
I. Romancero general: en que se contienen todos los romances que andan impresos. Aora nueuamente añadido y enmendado, en Madrid, por Iuan de la Cuesta, véndese en casa de Francisco Lopez, 1604, ff. 2r-v².

El romance aparece en la imprenta por primera vez en 1589 en F, pero debe ser anterior, ya que se recoge en A, de hacia 1581-1586. Su parodia, el romance realista bucólico «Ensíllenme el asno rucio», de Góngora, está fechado por el manuscrito Chacón en 1585, por lo que este texto parodiado ha de ser anterior a ese año.

Para la presente edición de «Ensíllenme el potro ruçio» tomamos como texto base A. Respetamos sus grafías excepto cuando lo corregimos con la ayuda de las demás fuentes manuscritas e impresas. La puntuación es nuestra. Hemos optado por editar el romance en cuartetas, ya que esta opción coincide con una práctica frecuente en impresores y autores de la época, quienes, seguramente influidos por el uso de cómo se cantaban los romances, los presentaban con frecuencia como composiciones en cuartetas octosilábicas; por otra parte, Góngora utiliza la cuarteta como unidad estructural para su parodia, por lo que resulta muy clarificador editar el texto de esta manera. En las notas, ponemos en primer lugar el aparato crítico de variantes al texto base y, a continuación, las notas explicativas separadas por $/ /$.

La versión de los cinco manuscritos (84 versos en total) es notablemente diferente de la de los impresos, ya que estos omiten 12 versos (o tres coplas), que señalamos en cursiva. Que se trata de una omisión y no de un añadido de los manuscritos lo corrobora la parodia de Góngora (también de 84 versos), que sigue casi al pie de la letra el texto de los manuscritos. Existe una correspondencia casi perfecta entre el poema parodiado y su parodia. Para componer su obra, Góngora utiliza la copla de cuatro versos como unidad semántica estructural y va siguiendo al pie de la letra el texto parodiado en su versión extensa, es decir, la de las fuentes manuscritas. Con dos únicas excepciones: para describir la medalla de Azarque el autor parodiado utiliza las dos coplas de los vv. 17-24, o sea, ocho versos; sin embargo Góngora emplea tres coplas, o sea, doce versos, para describir la patena. Después la parodia sigue las coplas parodiadas una a una, incluyendo las coplas de los vv 37-40 y de los vv. 61-64 que solo aparecen en las fuentes manuscritas. Por último, para ajustar el cómputo global de versos, deja sin respuesta la copla de los vv. 69-72, y vuelve a parafrasear las tres estrofas finales ${ }^{3}$.

${ }^{2}$ Utilizamos el ejemplar de la Biblioteca Nacional de España, U/897, que tiene notas manuscritas de Gallardo. Hay edición moderna, que no seguimos: Romancero general (1600, 1604, 1605), edición, prólogo e índices de Ángel González Palencia, 2 vols., Madrid, CSIC, 1947.

${ }^{3}$ El texto de la parodia gongorina se basa en la edición de Carreira (Antonio Carreira, ed., Luis de Góngora, Romances, 4 vols., Barcelona, Quaderns Crema, 1998, en el vol. I, n 17, págs. 345-346), pero hemos puntuado de manera levemente diferente en algún caso. 
Liñán ${ }^{4}$

«Ensíllenme el potro ruçio 5 del alcayde ${ }^{6}$ de Los Velez; denme la adarga de $\mathrm{Fez}^{8}$ y la jaçerina fuerte,

una lança con dos hierros, entrambos de agudo temple ${ }^{9}$, y aquel azerado caxco ${ }^{10}$ con el morado bonete,

que tiene plumas pagizas entre blancos martinetes, y garçotas medio pardas, antes que me vistan, denme.

Pondreme la toca azul ${ }^{12}$ que me dio para ponerme ${ }^{14}$ Adalifa la de Ocaña ${ }^{15}$, hija de Zelín Hamete ${ }^{16}$.

$\mathrm{Y}$ aquella medalla en quadro ${ }^{17}$ que dos ramos la guarnesçen ${ }^{18}$ con las hojas de esmeraldas ${ }^{19}$, por ser los ramos laureles,

\section{Góngora}

«Ensíllenme el asno rucio del alcalde ${ }^{7}$ Antón Llorente; denme el tapador de corcho y el gabán de paño verde,

el lanzón en cuyo hierro se han orinado los meses, el casco de calabaza y el vizcaíno machete;

y para mi caperuza las plumas del tordo denme, que por ser martín ${ }^{11}$ el tordo servirán de martinetes.

Pondreme el orillo ${ }^{13}$ azul que me dio para ponerme Teresa la del Villar, hija de Pascual Vicente.

$\mathrm{Y}$ aquella patena en cuadro donde de latón se ofrecen la madre del virotero $\mathrm{y}$ aquel dios que calza arneses,

\footnotetext{
${ }^{4}$ Solo en A.
}

${ }^{5}$ A: ençíllenme; B: ensíllame; C: ensílleme.

${ }^{6}$ alcaide: (Del ár. hispág. alqáyid, y este del ár. clás. qā’id, conductor [de tropas]). Hasta fines de la Edad Media, encargado de la guarda y defensa de algún castillo o fortaleza (DRAE).

${ }^{7}$ alcalde: (Del ár. hispág. alqáḍi, y este del ár. clás. qāḍi, juez). Juez ordinario que administraba justicia en algún pueblo y presidía al mismo tiempo el concejo (DRAE).

${ }^{8}$ C, D, G, H, I: el adarga; E: ladarga.

${ }^{9} \mathrm{H}, \mathrm{I}$ : agudos temples.

10 A: om. y.

11 Ponemos martín con minúscula por tratarse de un ave, a cuya especie pertenece, según el autor, el tordo; en lugar de plumas de martinete, otra ave (una garza), con que se adornaban los sombreros, se pondrá plumas de tordo, menos vistosas.

${ }^{12}$ A, D: pondrele una toca; B: pondrelle; C: porneme.

13 orillo: Orilla del paño o tejido en piezas, hecho, por lo regular, en un hilo más basto y de uno o más colores (DRAE).

${ }^{14} \mathrm{~A}$ : que me dio que le pusiesse; $\mathrm{B}, \mathrm{D}$ : que me dio para ponelle.

${ }^{15}$ F, G, I: la de Baça.

16 A: Selím.

${ }^{17} \mathrm{C}, \mathrm{E}$ : om. y.

${ }^{18} \mathrm{~F}$ : ramas.

${ }^{19} \mathrm{C}$ : esmeralda; E: desmeraldas. 
y un Adonis que va a caça ${ }^{20}$ de los javalíes monteses ${ }^{21}$ dexando a su diosa amada ${ }^{22}$, y dize la letra: MUERE» ${ }^{23}$.

Esto dixo el moro Açarque ${ }^{25}$ antes que a la guerra fuesse aquel discreto animoso ${ }^{26}$, aquel galán y valiente ${ }^{27}$

Almoralife de Baça ${ }^{28}$, de Zulemas desçendiente ${ }^{29}$, cavalleros $^{30}$ que en Granada passeavan $^{32}$ con los reyes.

Trajéronle la medalla ${ }^{34}$ $\mathrm{y}$, suspirando mill vezes, tan en pelota y tan juntos, que en nudos ciegos los tienen: al uno, redes y brazos; y al otro, brazos y redes;

cuyas figuras en torno acompañan y guarnecen ramos de nogal y espigas, y por letra: PAN Y NUECES» ${ }^{24}$.

Esto decía Galayo antes que al Tajo partiese aquel yegüero llorón, aquel jumental jinete,

natural de do nació, de yegüeros descendiente, hombres que se proveen ${ }^{31}$ ellos sin que los provean ${ }^{33}$ los reyes.

Trajéronle la patena ${ }^{35}$, $\mathrm{y}$, suspirando mil veces,

${ }^{20}$ A, B, C, D: om. y; C: casa.

${ }^{21} \mathrm{E}$ : de javalyes; F: con dos; G, H: con los.

${ }^{22} \mathrm{C}$ : dejando sola su diosa; B, F, G, I: dexando su diosa; E: que deja a su dama yngrata; H: dexando a Venus.

${ }^{23} \mathrm{El}$ emblema cuenta la historia de Venus y Adonis, con un presagio de la muerte del joven causada por Marte que se transforma en jabalí. Azarque está condenado a morir en la guerra.

${ }^{24}$ Pan es un eufemismo por cunnus y nueces por testes, como ya aparece en el Arcipreste de Hita: el pan de la panadera Cruz y la expresión «chica cosa es dos nueces». La pintura del emblema de la patena se refiere a Marte («aquel dios que calza arneses») y a Venus («la madre del virotero, Cupido»), apresados por el marido de esta, Vulcano, en una red, mientras fornicaban, «pan y nueces». Para explicar estos términos eróticos utilizamos el vocabulario del fundamental libro de Pierre Alzieu, Robert Jammes, Yvan Lissorgues, Poesía erótica del siglo de oro, Barcelona, Crítica, 2000. Véase también el artículo de Francisco Márquez Villanueva, «Pan "pudendum muliebris' y Los españoles en Flandes», en Hispanic Studies in Honor of Joseph H. Silverman, Edited by Joseph V. Ricapito, Newark, Delaware, Juan de la Cuesta, 1988, págs. 247-269.

25 E: esto dize el moro Azar.

${ }^{26} \mathrm{~F}$ : discreto y animoso. // «El Discreto» es el seudónimo de Liñán en su obra «La vida del pícaro».

27 B, C, D: y aquel.

28 A, F: Almoradife de Baça; B: Almoraliphe de Vaza; C omite los vv. 29-32; E: Almoralife en linaje; I: Almoralife el de Baça.

${ }^{29}$ A, B, C, D, E, F, H, I: Zulema.

$30 \mathrm{E}$ : cavallero.

${ }^{31}$ proveerse: Desembarazar, exonerar el vientre (DRAE).

${ }^{32} \mathrm{E}$ : paseaba.

33 proveer: Dar o conferir una dignidad, un empleo, un cargo, etc. (DRAE).

$34 \mathrm{~B}$, D: trujéronle.

35 patena: Lámina o medalla grande con una imagen esculpida, que se pone al pecho, y la usan para adorno las labradoras (DRAE). 
del bello Adonis mirava ${ }^{36}$

la gentileza y la suerte.

Piensa que será Adalifa ${ }^{38}$

Venus que los çisnes buelve ${ }^{40}$

al tiempo que no podía

gozarle ni socorrelle ${ }^{41}$.

«Adalifa de mi alma ${ }^{42}$, no te afflijas ni lo pienses ${ }^{43}$, biviré para gozarte ${ }^{44}$, gozosa vendrás a verme ${ }^{45}$.

Breve será mi jornada ${ }^{46}$, tu firmeza no sea breve; procura, aunque eres muger, ser a todas differente ${ }^{47}$.

No te parescas a Venus ${ }^{48}$, ya que en beldad le paresçes ${ }^{49}$, en olvidar a su amado ${ }^{50}$ $\mathrm{y}$ en no respetalle ausente ${ }^{51}$.
${ }^{36} \mathrm{G}$ : de vello.

${ }^{37}$ Galayo miraba en la patena «La dulce Francia (el orgasmo) y la suerte del dios garañón (Marte)».

${ }^{38} \mathrm{C}$ : piensa que la baleca (sic); F, G, H, I omiten los vv. 37-40.

${ }^{39}$ Esta es la prueba de que Góngora compone su parodia sobre una versión similar a la que nos transmiten los manuscritos, como testimonia esta copla y la correspondiente a los vv. 61-64. En la presente estrofa la degradación semántica del texto parodiado se muestra con toda claridad: Azarque piensa que su Adalifa, ante los presagios de su muerte que se derivan del emblema de la medalla, hará lo mismo que Venus: volver la rienda a los cisnes que tiran de su carro para acudir en ayuda de Adonis; en contraste, el celoso Galayo se imagina que su Teresa es Venus apresada en la red mientras fornicaba con Marte.

${ }^{40} \mathrm{~B}$ : zisnes muestre; E: que a los cisnes mueve.

${ }^{41}$ C: gozarse ni socorrerlle; D, E: gocalla ni socorrelle.

${ }^{42}$ A: Adalifa la de Ocaña; B: de mis ojos.

${ }^{43} \mathrm{E}$ : ni lamentes.

${ }^{44} \mathrm{C}$ : tubete para gozarte.

${ }^{45}$ D: goçosso vendás; E: gozoso bolveré a verte; G: a verte.

${ }^{46}$ A: la jornada; D: mi partida.

${ }^{47} \mathrm{E}, \mathrm{F}, \mathrm{G}, \mathrm{H}, \mathrm{I}$ : de todas.

${ }^{48}$ A, B, D, E, F, G, H: no le.

${ }^{49} \mathrm{C}$ : la que en la beldad pareçes; F, G, H, I: aunque en beldad.

${ }^{50} \mathrm{E}, \mathrm{F}, \mathrm{G}, \mathrm{H}, \mathrm{I}$ : a su amante.

${ }^{51} \mathrm{E}, \mathrm{F}, \mathrm{G}, \mathrm{H}, \mathrm{I}$ : y no.

${ }^{52}$ Venus, experta en infidelidades, en hacer de tantos huevos (testes) tantas frutas de sartenes (sartén: cunnus). 
Quando sola te imagines, mi retrato te consuele, sin admitir compañía ${ }^{53}$ que me ultrage y que te fuerçe $e^{54}$,

que entre consuelo y tristezas ${ }^{55}$ save Amor entremeterse ${ }^{56}$ haziendo de alegres tristes como de tristes alegres.

Y cómo si save Amor ${ }^{57}$; más que todos quantos leen, pues al sabio que enseñava ${ }^{59}$ niñas ay que le entorpeçen ${ }^{60}$.

Mira, amiga, mi retrato ${ }^{61}$, que abiertos ${ }^{62}$ los ojos tiene, y que es pintura ${ }^{63}$ encantada que habla, que bive y siente ${ }^{64}$.

Ay, no me ofendas, mi vida ${ }^{66}$; que sabré quanto hizieres ${ }^{67}$, y se trocarán en males nuestros amorosos bienes.

Acuérdate de mis ojos, que muchas lágrimas vierten, y a fe que lágrimas suyas pocas moras las meresçen ${ }^{68 " .}$
Cuando sola te imagines, para que de mí te acuerdes, ponle a un pantuflo aguileño un reverendo bonete.

Si creciere la tristeza, una lonja cortar puedes de un jamón, que bien sabrá tornarte de triste alegre.

Oh cómo sabe una lonja ${ }^{58}$ más que todos cuantos leen, y rabos de puercos más que lenguas de bachilleres.

Mira, amiga, tu pantuflo, porque verás, si lo vieres, que se parece a mi cara como una leche a otra leche ${ }^{65}$.

Acuérdate de mis ojos, que están, cuando estoy ausente, encima de la nariz y debajo de la frente».

${ }^{53} \mathrm{C}$ : con no admitir.

${ }^{54} \mathrm{~A}, \mathrm{~B}, \mathrm{D}$ : y que te esfuerce; C: que me hutrage; E: y que me afrente; F, G, H, I: y te desvele.

${ }^{55} \mathrm{~B}$ omite los vv. 57-64; C, D, E: tristeza; F, G, H, I: entre tristeza y dolor.

${ }^{56} \mathrm{H}$ : suele Amor entretenerse; E, F, G, H, I: suele Amor.

${ }^{57}$ C: om. y; E: y cómo save el Amor; F, G, H, I omiten los vv. 61-64.

58 Juega con la silepsis o dilogía de sabe (de sabor y de saber). Amor (Cupido) sabe mucho, pero más sabe una lonja de jamón. Es la concepción del mundo realista, a ras de tierra, de la mentalidad gongorina en este tipo de poemas.

${ }^{59} \mathrm{C}$ : enseñaste, $\mathrm{E}$ : al viejo.

${ }^{60} \mathrm{C}$ : lo entorpecen; E: niños ay que le entontezen. // Se refiere al cuento tradicional del sabio y las niñas.

${ }^{61} \mathrm{~A}$ : a mi retrato; B: mira amiga tu retrato.

${ }^{62} \mathrm{D}$ : abierto.

${ }^{63} \mathrm{~B}, \mathrm{C}, \mathrm{E}$ : figura.

${ }^{64} \mathrm{E}$ : que habla, vive y que syente.

${ }^{65}$ A partir de aquí la parodia se resuelve en tautologías, perogrulladas.

${ }^{66}$ B: y no me ofendas; E: offendas, mi alma; F, G, H, I omiten los vv. 69-72. // De esta estrofa se desentiende Góngora.

${ }^{67} \mathrm{E}$ : que he de saver quanto hicieres.

${ }^{68} \mathrm{E}$ : merezen. 
En esto llegó Aliazar ${ }^{69}$

y dízele que se apreste ${ }^{70}$

que davan prisa $^{71}$ en la mar

que se embarcase ${ }^{72}$ la gente.

A vençer se parte el moro, que, pues gustos no le vençen ${ }^{73}$ y honrra y esfuerço le animan ${ }^{74}$, cumplirá lo que promete ${ }^{75}$.
En esto llegó Bandurrio diciéndole que se apreste, que para sesenta leguas 80

«Ensíllenme el asno rucio» es un romance del realismo bucólico ${ }^{77}$, una parodia satírico-burlesca del romance idealista morisco anterior. Es una sátira personal o una burla contra el autor que se esconde tras el protagonista del romance parodiado, Azarque.

El romance parodiado «Ensíllenme el potro rucio» suele ser atribuido a Lope de $\mathrm{Vega}^{78}$, pero la única atribución antigua en A es al amigo de Lope, Pedro Liñán de Riaza. Carreira nos informa de que este romance «siempre se ha tenido por obra de Lope [...] pero [...] J. F. Montesinos ha alegado un pasaje de El lacayo fingido, considerada de Lope de Vega donde se cita con cierta sorna» ${ }^{79}$. Efectivamente Montesinos dice que la cita de El lacayo «es un caso más entre los infinitos en que los poetas burlan de la boga increíble alcanzada por algún romance famoso». Esta es la cita ${ }^{80}$.

${ }^{69}$ A, D, E: Galvano; C omite desde este verso 77 hasta el final del poema; F, G, H, I: Gualquemo.

${ }^{70}$ B: y le dijo; D: y le diçe; E, F, G, H, I: a dezille que.

${ }^{71} \mathrm{E}$ : priesa; G: priessa.

${ }^{72} \mathrm{E}$ : a que se envarque.

${ }^{73} \mathrm{~F}, \mathrm{G}, \mathrm{H}, \mathrm{I}$ : aunque gustos.

${ }^{74}$ Todos menos A omiten y; B, D, F: le animan; E: honrra les vençe y anyma; G, H, I: lo animan.

${ }^{75} \mathrm{E}$ : a cumplir lo que prometen; F, G, H, I: a cumplir.

${ }^{76}$ tajo (echar un tajo: futuere); broquel: cunnus.

${ }^{77}$ El concepto de «Realismo bucólico» fue acuñado por José F. Montesinos para calificar una nueva manera de hacer poesía bucólica en el Romancero nuevo, iniciada quizá por Pedro Liñán de Riaza en los últimos años del siglo XVI y que se desarrollaría plenamente en los primeros años del siglo XVII (Primavera y flor de los mejores romances recogidos por el licenciado Arias Pérez, Madrid, 1621), reimpreso directamente de la primera edición con un estudio preliminar de J. Fernández Montesinos, Castalia, Valencia, 1954, págs. XLVIII-LI; Romancerillos tardíos, ed. J. Fernández Montesinos, Salamanca, Anaya, 1964, págs. 22-23: «El nuevo bucolismo»).

${ }^{78}$ Por ejemplo, por Antonio Carreño, ed., Lope de Vega, Rimas humanas y otros versos, Barcelona, Crítica, 1998, págs. 18-21. Para su texto, se basa solo en los impresos F, G e I.

${ }^{79}$ Antonio Carreira, ed. cit., vol. I, no 17, págs. 345-346.

${ }^{80}$ José F. Montesinos, Estudios sobre Lope de Vega, Anaya, Salamanca, 1989, pág. 281. Es muy significativo que Montesinos en su antología de los romances moriscos de Lope no incluyera «Ensíllenme el potro rucio» (Lope de Vega, Poesías líricas, 2 vols., Madrid, Espasa-Calpe, S. A., Clásicos Castellanos, 1960, los romances moriscos en el vol. I, págs. 41-58). 
- ¡Ojo!, pidiendo viene el potro rucio.

- Pues hace mal viniendo a pie el cuitado.

La atribución a Lope sólo está basado en un presunto autobiografismo de su contenido, pero ese autobiografismo sería también aplicable a Liñán que sabemos que participó en una expedición naval ${ }^{81}$. Y quizá también a otros autores. Pero A, un testimonio contemporáneo, lo atribuye a Liñán y este hecho debe tener más fuerza que cualquier conjetura.

El protagonista del romance es Azarque. Según la ficción inventada del poema, este personaje es un Almoralife de Baza, perteneciente a los Zulemas, una estirpe de caballeros moros de esa localidad granadina, tan alta que paseaban con los reyes de Granada. Azarque ama a una Adalifa a la que todos los manuscritos y el impreso H llaman «la de Ocaña», frente a «la de Baza» de los impresos F, G e I. La lectura «la de Baza» puede tratarse de una contaminación por el sintagma «de Baza» del verso 29. Parece, pues, preferible, por originaria y más temprana, la lectura «la de Ocaña». Lo cual nos llevaría a situar este romance como uno de los pertenecientes al ciclo de Azarque de Ocaña.

No habría que descartar que todo el ciclo de Azarque fuera el producto de la colaboración de los dos amigos, de Lope y de Liñán (que habrían compuesto diferentes romances sobre el mismo personaje), como sospechamos que pudieron colaborar en algunas obras de teatro atribuidas a Lope y como estamos seguros de que lo hicieron en el ciclo romanceril del pastor Simocho, de la época de Alba de Tormes. Los dos amigos trabajaban juntos: fundaron una academia en Toledo en la que ambos, Riselo y Belardo, reinaban como poetas máximos, se intercambiaron sonetos, larguísimos poemas en tercetos, se elogian y se defienden el uno al otro en multitud de ocasiones.

El manuscrito salmantino $\mathrm{A}$, de los años ochenta, incluye varios romances de este ciclo y otros en que se menciona a los moros Almoralifes y los atribuye todos a Liñán: «Azarque bive en Ocaña» (f. 392v), «El mejor Almoradife» (f. 399r), «Azarque indignado y fiero» (f. 401r), «Alcaide moro Aliatar» (f. 402r). Las referencias a Ocaña son constantes en los poemas de Liñán, así en el romance «Galliana está en Toledo» (f. 402v), su galán, Abenámar, «por las riberas del Tajo / se fue camino de Ocaña». Si el único testimonio contemporáneo conservado (el del manuscrito A) atribuye estos romances de Azarque de Ocaña a Liñán, quizá habría que concluir que «Ensíllenme el potro rucio», sería otro romance de este ciclo y atribuible, por tanto, al mismo.

${ }^{81}$ Como se deduce de algunas de sus composiciones. Véase Pedro Liñán de Riaza, Poesías, edición, introducción y notas de Julian F. Randolph, Barcelona, Puvill Libros S. A., 1982, nº 44, pág. 286-289: «De la naval con quien fueron / tan inclementes los hados». 
Azarque es el seudónimo morisco principal de Liñán. En su poema titulado «Confesión», que comienza «Los que mis culpas oísteis», reniega de sus seudónimos pastoriles y moriscos respectivamente ${ }^{82}$ :

De tantos romances moros, de tantas fieles endechas pido perdon a los cascos de mil quebradas cabezas Que ya Riselo y Azarque será mejor que se mueran y que de la tierra hablen, pues que en efecto son tierra.

Con el sintagma fieles endechas se refiere a sus romances pastoriles. Se ve claramente que su seudónimo pastoril principal ha sido Riselo; y el morisco, Azarque. Liñán está reivindicando ese seudónimo para sí y no consta que Lope de Vega haya hecho algo semejante.

Liñán escribió también el poema en tercetos «La vida del pícaro», leído ante una academia antes de 1595 (El ms. 17556 de la BNE, en donde se conserva, es de hacia 1595, según su editora $\left.{ }^{83}\right)$. En esta composición, Liñán se dio a sí mismo el nombre académico de «el Discreto» (vv. 325-330) ${ }^{84}$ :

Forçoso me es callar, mi musa quiere ponerse en sus chapines de respeto y engalanarse más, si más pudiere.

Académicos míos, que al Discreto discretamente acariçiáis en todo, no deis a mi rudeza nuevo reto.

La misma expresión, referida a Azarque, aparece en el v. 27 del romance parodiado («aquel discreto animoso»). Tenemos además el romance morisco «Bravonel de Zaragoza», atribuido a Liñán en el manuscrito D, y aceptada esta atribución por la crítica. Cuando en este poema se describe una empresa pintada en la adarga de Bravonel, semejante a la pintada en la medalla en el romance «Ensíllenme el potro ruçio», se dice:

$$
\begin{aligned}
& \text { Una adarga ververisca } \\
& \text { con su divisa pintada } \\
& \text { tan discreta como el dueño } \\
& \text { y como el dueño mirada }{ }^{85} \text {. }
\end{aligned}
$$

\footnotetext{
${ }^{82}$ Ibídem, nº 48, pág. 302.

${ }^{83}$ Es el manuscrito D, editado por Goldberg, Poesías barias, tomo II, págs. 423-433.

${ }^{84}$ Pedro Liñán de Riaza, Poesías, ed. cit., nº 6, pág. 146.

85 Ibídem, no 35, pág. 260.
} 
Tanto Bravonel como Azarque son dos discretos, lo mismo que Liñán. Es una palabra recurrente de Liñán para referirse a sí mismo, que emplea en algunas otras de sus obras.

En «La vida del pícaro» hay también una alusión al contenido de «Ensíllenme el potro rucio» en los vv. 223-225:

No ay pícaro que usurpe ageno trato, no sabe lo que es peine ni escobilla, garçotas, martinetes, ni retrato.

El pícaro desconoce estos elementos del atuendo y de la vida de un noble, moro o no. Las garçotas aparecen en el v 11 de «Ensíllenme el potro rucio», los martinetes en el v. 10, y el retrato en los vv. 65-76. Liñán está citando palabras que le son familiares, que él pudo haber empleado en otra ocasión.

Para atribuir la obra a Lope de Vega la crítica suele invocar cinco romances que aluden al potro rucio: «Desensíllenme la yegua», en H, ff. 206v-208v; «Toquen a priesa a rebato», en $\mathrm{I}^{86}, \mathrm{n}^{\circ} 584$; «Lleve el diablo el potro rucio», en I, n 605 ; «¿Qué se me da a mí que el mundo?», en I, nº 856; y «Valga el diablo tantos moros», en I, $\mathrm{n}^{\mathrm{o}} 1043$. Todos ellos son romances anónimos y, por tanto, las alusiones en ellos son problemáticas, si no se ha logrado despejar ese anonimato previamente.

Sin embargo, estudiando el Manojuelo de romances de Gabriel Lasso de la Vega, edición de Zaragoza de $1601^{87}$, hemos descubierto varios datos de los que ya hemos hablado en un artículo nuestro anterior ${ }^{88}$ : Lasso de la Vega satiriza a Liñán de Riaza en varios poemas de este libro. La relevancia de lo que dice - frente a los anteriores romances anónimos citados - se deriva del hecho de que no son palabras anónimas, son suyas, y Lasso se hace responsable de ellas al publicarlas bajo su nombre. En su romance n 9 (págs. 28-31), «Señor moro vagabundo / que el viejo acebuche esconde», se está burlando del romance morisco ${ }^{89}$ de Liñán «A sombras de un acebuche» ${ }^{90}$. En los versos 61 al 66 Lasso de la Vega le atribuye la autoría de «Ensíllenme el potro rucio»:

Válgate el diablo por moro, que ansí has cansado los hombres

\footnotetext{
${ }^{86}$ Los números se refieren a la edición de González Palencia citada.

${ }^{87}$ Hay edición moderna de este libro: Gabriel Lasso de la Vega, Manojuelo de romances, edición de Ángel González Palencia y Eugenio Mele, Madrid, Saeta, 1952.

88 José Luis Pérez López, «Nuevos poemas atribuibles a Pedro Liñán de Riaza (con un estudio de las obras de Gabriel Lasso de la Vega)», Voz y Letra, XIX/1, 2007, págs. 99-139, en las págs. 130-132.

${ }^{89}$ Liñán y Lope son los principales autores de los romances moriscos; Lasso los atacó directa y duramente en varios romances como este. Es probable que el último romance anónimo también citado en el párrafo anterior, «Valga el diablo tantos moros» (en I, n 1043) sea también de Lasso.

90 Véase Pedro Liñán de Riaza, Poesías, ed. cit., págs. 272-273, nº 40.
} 


$$
\begin{aligned}
& \text { con tu larga soledad } \\
& \text { y melancólicas noches. } \\
& \text { El potro rucio te dé } \\
& \text { en la barriga seis coces. } \\
& \text { Y quien amén no dijere } \\
& \text { en malas galeras bogue. }
\end{aligned}
$$

La parodia gongorina «Ensíllenme el asno rucio» nos suministra otros datos adicionales para su atribución a Liñán. Góngora convierte al protagonista idealizado del romance morisco, Azarque de Ocaña, un caballero moro (el ascenso social permanente de Lope y de Liñán en el romancero morisco), en un rústico personaje burlesco, de carnaval, el villano Galayo, un personaje del realismo bucólico del que habló Montesinos ${ }^{11}$.

Si el romance de Azarque presenta al protagonista como un noble caballero moro cuya estirpe es tan alta que se relaciona con los reyes de Granada, su parodia lo presenta como un rústico villano con caperuza. Góngora estaría atacando al autor del romance poniendo de relieve su origen humilde, lo mismo que hizo contra Lope en el conocido soneto «Por tu vida, Lopillo, que me borres / las diez y nueve torres de tu escudo» ${ }^{92}$, en el que destaca su carácter de villano como el hijo de un bordador de casullas que era: «Oh brazos Leganeses y Vinorres».

El protagonista de la parodia, que nos habla directamente y de manera abrupta al comienzo, no se va a ninguna expedición naval (v. 30), se va a Toledo. ¿Es una denuncia de Góngora de que el protagonista no fue a ninguna expedición naval? Su noble estirpe mora se convierte en la de un yegüero llorón (v. 34). Le califica además de jumental jinete, jinete no de potros sino de jumentos. Jumental tiene además una connotación sexual inequívoca (construido sobre semental). Galayo tiene vocación de garañón, por eso en la parodia mira con envidia la suerte de Marte, «el dios garañón», con Venus. Y reitera esa vocación de semental en los versos finales (81-84) en que el narrador emplea nuevos eufemismos sexuales: los tajos que piensa dar en Toledo el bobo Galayo en mil hermosos broqueles femeninos.

Dice también que Galayo (v. 36) pertenece a esas gentes que «se proveen ellos», «defecan», pero no consiguen ningún puesto, oficio público, de los reyes («sin que los provean los reyes»). Es una nueva malicia contra las aspira-

\footnotetext{
${ }^{91}$ Véase mi artículo José Luis Pérez López, «Los romances del realismo bucólico de Liñán de Riaza y de Lope de Vega, el 'Entremés de los romances' y el Quijote», Anuario Lope de Vega, volumen XV, 2009, págs. 169-201. «Ensíllenme es asno rucio» de Góngora es uno de los romances que vertebran la trama del «Entremés de los romances». En él aparece también Bandurrio.

${ }^{92}$ Luis de Góngora, Sonetos completos, ed. Biruté Ciplijauskaité, Madrid, Castalia, 1978, pág. 261.
} 
ciones de ascenso social que hemos detectado en esa época en Liñán, que se ponen de relieve en su romance «¿Qué te hice, vil Fortuna?» ${ }^{93}$.

En el v. 60, el autor, Góngora, hace decir a Galayo que su cara es como un pantuflo $^{94}$ al que se le pusiera un bonete de clérigo o de estudiante. Parte de la crítica considera que el autor, el clérigo Góngora, está haciendo una caricatura de sí mismo. Pero aquí hay una incongruencia textual que es necesario destacar: el personaje que se esconde tras el nombre de Galayo no es el propio Góngora (no se va a satirizar a sí mismo llamándose bobo y jumental, por ejemplo, entre otras flores), por tanto debe de referirse a otra persona. Tampoco encaja ponerle un bonete clerical a Lope de Vega, del que no se sabe que vistiera como clérigo o como estudiante en esta época. El que sí vestía el habito clerical de estudiante (al igual que Góngora) era el bachiller Liñán (él mismo se refiere a este hábito clerical - la «hipocresía del manteo y la sotana», dice- en su romance citado «Qué te hice, vil Fortuna»). El bonete y el pantuflo no se refieren, por tanto, a Góngora, porque el que habla es el personaje Galayo y no el narrador-autor, Góngora. Tampoco el apelativo Bandurrio (v. 77) debe de referirse a Góngora. Bandurrio es el amigo de Galayo. Cosa muy distinta es que después sus adversarios le devolvieran el apelativo a Góngora y le llamaran Bandurrio, como hizo Lope en La Dorotea, pero eso fue muchos años después, en $1632^{95}$. La congruencia interna del poema exige que la caricatura del pantuflo y el bonete y el apelativo de Bandurrio se refieran a unos personajes distintos del narrador que nos habla, Góngora. No olvidemos tampoco que uno de los poemas que escribió Liñán de Riaza, según nos dice el romance «Ah, qué dellos ha espantado», es «Topó al ciego virotero» ${ }^{96}$. En este romance el dios Cupido encuentra a un arriero que se queda en una venta con una moza asturiana:

Diole con una corita con mas boca que un pantuflo, con quien se quedó en la venta que passar de allí no pudo ${ }^{97}$.

\footnotetext{
93 Véase José Luis Pérez López, «Una hipótesis sobre el Don Quijote de Avellaneda: de Liñán de Riaza a Lope de Vega», Lemir (revista electrónica), nº 9, 2005.

${ }^{94}$ Según el DRAE, pantuflo es «Calzado, especie de chinela o zapato sin orejas ni talón, que para mayor comodidad se usa en casa».

$95 \mathrm{Si}$ es que la alusión «Como en el tiempo del pastor Bandurrio» se refiere a Góngora. Véase Lope de Vega, La Dorotea, edición, introducción y notas de Edwin S. Morby, Madrid, Castalia, 1987, págs. 387-388.

96 Véase mi artículo citado J. L. Pérez López, «Nuevos poemas atribuibles a Pedro Liñán de Riaza...», págs. 99-139.

${ }^{97}$ I, Dozena parte, ff. 441v-442v, vv. 113-116. Diole, le encontró con una corita (asturiana, montañesa o vizcaína) de una gran boca. Recordemos que también el pastor Simocho, protagonista de otra obra de Liñán, tenía «más boca que un becerro». Es bien sabida la creencia de la época de que el tamaño de la boca femenina se correspondía con el del cunnus.
} 
Góngora está atacando (v. 68) a la lengua de un bachiller (lengua se emplea como metonimia de injurias y de insidias). Como es bien sabido, Liñán se graduó como bachiller por Salamanca, donde coincidió con Góngora, en esta década de los ochenta, según nos lo dice el propio Lope tiempo después, en 1621, en una alusión llena de reticencias contra el cordobés en La Filomena:

De sus estudios me dijo mucho Pedro Liñán de Riaza, contemporáneo suyo en Salamanca, de suerte que non indoctus pari facundia, et ingenio praeditus, rindió mi voluntad a su inclinación, continuada con su vista y conversación, pasando a la Andalucía ${ }^{98}$.

Vemos que Lope toma a Liñán como amigo incondicional cuya opinión de otra persona (Góngora) es aceptada sin reparos. En la reticencia del «me dijo mucho» podría estar la clave que explicaría este ataque de Góngora a su antiguo condiscípulo. Ese mucho no sería nada bueno.

La utilización de la palabra bachiller en la parodia gongorina es, pues, despectiva. El licenciado Góngora desprecia al baccalauro Liñán. El estudiante de origen noble, Góngora, desprecia al bachiller capigorrón y snob, Liñán: este — dice Góngora en su parodia- no es Azarque, un noble caballero moro con un destino trágico, sino Galayo, un rústico villano con caperuza, un yegüero llorón, merecedor de que su Teresa lo encornude.

La saña del cordobés contra Liñán de Riaza no terminó ahí. Se sabía que la historia gongorina de Galayo y de Teresa que aparece en «Ensíllenme el asno rucio» tenía una continuación en el durísimo romance satírico de Góngora «En la pedregosa orilla / del turbio Guadalmellato» ${ }^{99}$, con los mismos protagonistas, Galayo y Teresona. Pero a la vista de esta relación entre Góngora y Liñán de la que venimos hablando (desconocida hasta ahora para la crítica) surge una nueva posibilidad: en ese nuevo romance, Góngora puede estar parodiando otro romance idealista bucólico de Liñán: «Al tiempo que el alba bella» ${ }^{100}$, que ahora tiene como protagonista al otro seudónimo pastoril de Liñán, el pastor Riselo. Si la parodia de «Ensíllenme el potro rucio» suponía la destrucción del género idealista morisco, en esta, Góngora va a hacer lo mismo con el género idealista pastoril arcádico.

Creemos que todos estos argumentos - y el principal es el de su atribución a Liñán de Riaza en A, un manuscrito salmantino de esos años ochenta, cuyo compilador debió de estar cerca de ambos autores - nos llevan a su autoría mientras no se aporte un testimonio de mayor relevancia a favor de la de Lope

${ }^{98}$ Lope de Vega, «Respuesta de Lope de Vega Carpio» a un «Papel que escribió un señor de estos reinos a Lope de Vega Carpio en razón de la nueva poesía», La Filomena. Poesía IV, edición y prólogo de Antonio Carreño, Madrid, Biblioteca Castro, 2003, pág. 311.

99 Véase en A. Carreira, ed. cit., vol. I, nº 9, págs. 245-253.

100 Véase en Pedro Liñán de Riaza, Poesías, ed. cit., nº 4, págs. 189-190. 
de Vega. Si esto fuera así, la parodia gongorina «Ensíllenme el asno rucio» debe ser enfocada con esta perspectiva nueva y distinta que estamos considerando y, además, nos estaría avisando de la necesidad de dejar de utilizar presuntos rasgos biográficos de Lope de Vega para atribuirle romances anónimos sin otros argumentos de mayor solidez.

\section{BIBLIOGRAFÍA}

Alzieu, Pierre, Jammes, Robert y Lissorgues, Yvan, Poesía erótica del siglo de oro, Barcelona, Crítica, 2000.

Fernández Montesinos, José, ed., Los Romancerillos tardíos, Salamanca, Anaya, 1964.

Fernández Montesinos, José, Estudios sobre Lope de Vega, Salamanca, Anaya, 1989.

Goldberg, Rita, ed., Poesías barias y recreación de buenos ingenios, Madrid, José Purrúa Turanzas, 1984.

Góngora, Luis de, Romances, Antonio Carreira, ed., Barcelona, Quaderns Crema, 1998.

Góngora, Luis de, Sonetos completos, Biruté Ciplijauskaité, ed., Madrid, Castalia, 1978.

Lasso de la Vega, Gabriel, Manojuelo de romances, Ángel González Palencia y Eugenio Mele, eds., Madrid, Saeta, 1952.

Liñán de Riaza, Pedro, Poesías, Julián F. Randolph, ed., Barcelona, Puvill Libros S. A., 1982.

Márquez Villanueva, Francisco, «Pan 'pudendum muliebris' y Los españoles en Flandes», Hispanic Studies in Honor of Joseph H. Silverman, Joseph V. Ricapito, ed., 1988, págs. 247-269.

Pérez López, José Luis, «Los romances del realismo bucólico de Liñán de Riaza y de Lope de Vega, el 'Entremés de los romances' y el Quijote», Anuario Lope de Vega, vol. XV, 2009, págs. 169-201.

Pérez López, José Luis, «Nuevos poemas atribuibles a Pedro Liñán de Riaza (con un estudio de las obras de Gabriel Lasso de la Vega)», Voz y Letra, XIX, 1, 2007, págs. 99-139.

Pérez López, José Luis, «Una hipótesis sobre el Don Quijote de Avellaneda: de Liñán de Riaza a Lope de Vega», Lemir (revista electrónica), 9, 2005.

Primavera y flor de los mejores romances recogidos por el licenciado Arias Pérez (Madrid, 1621), reimpreso directamente de la primera edición con un estudio preliminar de J. Fernández Montesinos, Castalia, Valencia, 1954.

Real Academia Española, Diccionario de la lengua española, Madrid, Espasa-Calpe, 2001.

Rodríguez-Moñino, Antonio, ed., Las fuentes del Romancero general (Madrid, 1600), Madrid, RAE, 1957.

Romancero general (1600, 1604, 1605), edición, prólogo e índices de Ángel González Palencia, 2 vols., Madrid, CSIC, 1947.

Vega, Lope de, La Dorotea, Edwin S. Morby, ed., Madrid, Castalia, 1987.

Vega, Lope de, La Filomena. Poesía IV, Antonio Carreño, ed., Madrid, Biblioteca Castro, 2003.

Vega, Lope de, Poesías líricas, José F. Montesinos, ed., Madrid, Espasa-Calpe, S. A., Clásicos Castellanos, 1960.

Vega, Lope de, Rimas humanas y otros versos, Antonio Carreño, ed., Barcelona, Crítica, 1998.

Fecha de recepción: 15 de enero de 2010

Fecha de aceptación: 27 de septiembre de 2010 